\title{
The epidemiological characteristics of deaths with COVID-19 in the early stage of epidemic in Wuhan, China
}

Jianjun Bai ${ }^{1 \dagger}$, Fang Shi ${ }^{1 \dagger}$, Jinhong Cao ${ }^{1}$, Haoyu Wen ${ }^{1}$, Fang Wang ${ }^{1}$, Sumaira Mubarik ${ }^{1}$, Xiaoxue Liu ${ }^{1}$, Yong Yu ${ }^{2}$, Jianbo Ding ${ }^{3}$ and Chuanhua $\mathrm{Yu}^{1,4^{*}}$

\begin{abstract}
Objectives: To analyze the epidemiological characteristics of COVID-19 related deaths in Wuhan, China and comprehend the changing trends of this epidemic along with analyzing the prevention and control measures in Wuhan.

Methods: Through the China's Infectious Disease Information System, we collected information about COVID-19 associated deaths from December 15, 2019 to February 24, 2020 in Wuhan. We analyzed the patient's demographic characteristics, drew epidemiological curve and made geographic distribution maps of the death toll in each district over time, etc. ArcGIS was used to plot the numbers of daily deaths on maps. Statistical analyses were performed using SPSS and @Risk software.

Results: As of February 24, 2020, a total of 1833 deaths were included. Among the deaths with COVID-19, mild type accounted for the most (37.2\%), followed by severe type (30.1\%). The median age was 70.0 (inter quartile range: 63.0-79.0) years. Most of the deaths were distributed in 50-89 age group, whereas no deaths occurred in 09 age group. Additionally, the male to female ratio was 1.95:1. A total of $65.7 \%$ of the deaths in Wuhan combined with underlying diseases, and was more pronounced among males. Most of the underlying diseases included hypertension, diabetes and cardiovascular diseases. The peak of daily deaths appeared on February 14 and then declined. The median interval from symptom onset to diagnosis was 10.0 (6.0-14.0) days; the interval from onset to diagnosis gradually shortened. The median intervals from diagnosis to death and symptom onset to deaths were 6.0 (2.0-11.0), 17.0 (12.0-22.0) days, respectively. Most of the disease was centralized in central urban area with highest death rate in Jianghan District.

Conclusion: COVID-19 poses a greater threat to the elderly people and men with more devastating effects, particularly in the presence of underlying diseases. The geographical distributions show that the epidemic in the central area of Wuhan is more serious than that in the surrounding areas. Analysis of deaths as of February 24 indicates that a tremendous improvement of COVID-19 epidemic in Wuhan has achieved by effective control measures taken by Wuhan Government.
\end{abstract}

Keywords: COVID-19, Coronavirus disease 2019, Wuhan city, Epidemiological characteristic, Death

\footnotetext{
* Correspondence: yuchua@whu.edu.cn

${ }^{\dagger}$ Jianjun Bai and Fang Shi contributed equally to this work.

'Department of Epidemiology and Biostatistics, School of Health Sciences,

Wuhan University, 115\#Donghu Road, Wuhan 430071, China

${ }^{4}$ Global Health Institute, Wuhan University, 185\# Donghu Road, Wuhan

430072, China

Full list of author information is available at the end of the article
}

(c) The Author(s). 2020, corrected publication 2020. Open Access This article is licensed under a Creative Commons Attribution 4.0 International License, which permits use, sharing, adaptation, distribution and reproduction in any medium or format, as long as you give appropriate credit to the original author(s) and the source, provide a link to the Creative Commons licence, and indicate if changes were made. The images or other third party material in this article are included in the article's Creative Commons licence, unless indicated otherwise in a credit line to the material. If material is not included in the article's Creative Commons licence and your intended use is not permitted by statutory regulation or exceeds the permitted use, you will need to obtain permission directly from the copyright holder. To view a copy of this licence, visit http://creativecommons.org/ licenses/by/4.0/. 


\section{Introduction}

The outbreak of new infectious diseases in recent years has caused great losses to human health, quality of life and economy. Millions of infections were caused worldwide by Severe Acute Respiratory Syndrome Coronavirus (SARS-CoV) in 2003, Middle East Respiratory Syndrome Coronavirus (MERS-CoV) in 2012, Ebola virus in 2014, Zika virus in 2015, and the plague in Madagascar in 2017 [1-3].

In December 2019, a new coronavirus began to spread in Wuhan and even the whole country. On December 31, an alert was issued by the Wuhan Municipal Health Commission and a rapid response team was sent to $\mathrm{Wu}$ han by the Chinese Center for Disease Control and Prevention (China $\mathrm{CDC}$ ). Epidemiological investigation implicated that this pneumonia epidemic was different from the previous ones and Wuhan Huanan Seafood Wholesale Market may be a possible source of infection. On January 1, the Huanan Seafood Wholesale Market was shut down. On January 20, China's "National Infectious Diseases Law" was amended to make 2019-novel coronavirus diseases (COVID-19) a Class B notifiable disease and its "Frontier Health and Quarantine Law" was amended to support the COVID-19 outbreak response effort. On January 23, the Chinese Government began to limit movement of people in and out of Wuhan. As of February 5, two newly established COVID-19 designated hospitals and several mobile cabin hospitals have been opened.

The WHO officially named this unexplained pneumonia as Coronavirus Disease 2019 (COVID-19) on February 11, 2020. Based on the genetic structure of the virus, the International Committee on Taxonomy of Viruses officially named the virus as Severe Acute Respiratory Syndrome Coronavirus 2 (SARS-CoV-2) [4], which is more contagious than both of the previous forms (SARSCoV and MERS-CoV).

On March 11, the WHO officially declared the epidemic caused by COVID-19 as Pandemic. This is the first time in this century that coronavirus infection (SARS, MERS, COVID-19) has been evaluated as Pandemic.

As of February 24, 2020, 77,658 cases diagnosed with COVID-19 had been reported in Mainland China, among which 64,786 (83.42\%) cases were reported in Hubei Province and 47,071 (60.61\%) were in Wuhan city. Among the 2663 deaths across Mainland China, 2563 (96.24\%) deaths occurred in Hubei Province and 2043 (76.72\%) deaths in Wuhan city. The epidemiological features of COVID-19 cases are crucial for the development and implementation of effective control measures. In this study, we retrospectively collected and described detailed epidemiological and demographic characteristics of deaths caused by COVID-19 in Wuhan to understand the changes of the COVID-19 epidemic and the effects of prevention and control measures in Wuhan, China.

\section{Methods}

\section{Data sources}

As a retrospective cross-sectional study, all data were extracted from China's Infectious Disease Information System. Specific details of data collection were provided elsewhere [5]. Through the Wuhan Statistics Bureau, the permanent resident population of Wuhan in 2018 was 11.081 million. After eliminating the duplicate data, a total of 1833 deaths were included in the study. We removed duplicate data based on the name, ID number and gender. If the name, ID number and gender of the case were the same, then the duplicate data were removed. A total of 59 duplicate entries were excluded before proceeding towards analyses.

\section{Variables}

Demographic data consisted of information on age, sex, occupation, residential area, area of reporting units. Other available data included clinical outcomes, disease severity, report date, date of onset, date of diagnosis, date of death, the interval time from onset to diagnosis, the interval time from diagnosis to death and the interval time from onset to death. The underlying disease variable was determined using patient self-reported history. The severity of symptoms were categorized as mild type, common type, severe type or critical type, the detailed classification criteria were shown in Supplementary Table S1. The crude death rate was estimated as the number of deaths divided by the number of permanent resident population of Wuhan. The date of onset was defined as the day when the symptom was observed.

\section{Statistical analysis}

We present continuous variables as medians (interquartile ranges, IQR) and compared using Mann-Whitney $U$ test. If they are normally distributed, we present continuous variables as mean (Standard Deviation, SD). Categorical variables were described as counts and percentages in each category. The probability distributions of age and interval time were fitted and the distribution with the lowest AIC value was selected as optimal distribution. The map of epidemic situation in Wuhan was drawn based on the number of daily deaths. We used ArcGIS to plot the numbers of daily deaths on maps. Statistical analyses were performed using SPSS and @Risk software.

\section{Ethics approval}

Data collection, which determined by the National Health Commission of the People's Republic of China, 
was exempt from institutional review board approval because it was part of outbreak investigation. Study design and data analysis have been reviewed and approved by the Medical Ethical Committees of Wuhan University (WHU2020-2020YF0031).

\section{Results}

\section{Patients}

As of February 24, 2020, a total of 1833 unique deaths with COVID-19 were included in the analysis. Baseline characteristics of deaths are presented in Table 1. According to our database, the first death occurred on January 9, 2020. A majority were aged 50-89 years (89.9\%), male (66.1\%), retirees (46.7\%). Eight health workers died with COVID-19. Among the composition of disease severity, mild type accounted for the largest proportion (37.2\%), followed by severe type(30.1\%), then $13.6 \%$ for critical type and $5.5 \%$ for common type.

\section{Age distribution and sex ratio}

The age of deaths obeyed the Weibull distribution $(8.2152,89.42,-14.41)$ illustrated in Table 1 . The minimum, maximum and median ages of the deaths were 14.0, 100.0 and 70.0 (IQR: 63.0-79.0), respectively. The number of deaths due to COVID-19 between the ages of $50-89$ years was 1647 , accounting for $89.9 \%$ of the total deaths, and the age distribution of different disease severity was similar.

Among the 1833 deaths, male deaths accounted for $66.1 \%$, and the male to female ratio was 1.95:1 in Wuhan. As shown in Fig. 1, in all age groups, male deaths were significantly more than female deaths. The male to female ratio of different disease severity was similar.

\section{Underlying diseases}

There were 1204 COVID-19 deaths with underlying diseases $(65.7 \%)$ and 676 deaths with more than one underlying disease (56.2\%). Among these underlying diseases, hypertension accounts for the largest proportion$61.6 \%$, then $29.7 \%$ for diabetes, $27.4 \%$ for cardiovascular diseases, $12.6 \%$ for respiratory diseases, and $6.8 \%$ for cancer.

The median age of deaths with underlying diseases (M: 72.0 IQR: 64.0-79.0) was higher than that of those who died without underlying diseases (M: 68.0 IQR: 60.0-76.0) $(P<0.001)$. In addition, there were 820 male deaths and 384 female deaths with underlying diseases, the male to female ratio for deaths with underlying diseases was 2.14:1.

\section{Temporal distribution}

Figure 2 shows the COVID-19 epidemic curve with number of deaths plotted by date of patient's onset of symptoms, diagnosis and death. The peak onset of symptoms for COVID-19 deaths occurred on January 23, 2020. Since then, onset of illness has declined. The number of diagnosis reached the peak of 122 on February 1,2020 , and the daily deaths reached the peak of 97 on February 14.

As shown in Fig. 3. The median interval from symptom onset to diagnosis was 10.0 (IQR: 6.0-14.0) days and obeyed the Log Logistic distribution. Moreover, for those whose onset date was before January 15, between January 15-31, and after January 31, the median intervals from onset to diagnosis were 15.0, 11.0, and 5.0 days, respectively. The interval from onset to diagnosis gradually shortened, the efficiency of diagnosis is improving. In addition, The median of interval from onset to diagnosis for 746 cases before January 23 was 13.0 days (IQR: 10.0-18.0), which was significantly longer than the 1058 cases after January 23 with a median of 8.0 days (IQR: $5.0-12.0)(p<0.001)$. The median interval from diagnosis to death was 6.0 (IQR: 2.0-11.0) days and obeyed the InvGauss distribution. The median interval from symptom onset to deaths was 17.0 (IQR: 12.022.0) days and obeyed the Log Logistic distribution. The distribution fit is shown in Table 2.

\section{Geographical distribution}

A total of 13 administrative regions constitute Wuhan, of which Jiang'an District, Jianghan District, Qiaokou District, Hanyang District, Wuchang District, Qingshan District and Hongshan District are the central urban area, Dongxihu District, Hannan District, Caidian District, Jiangxia District, Huangpi District and Xinzhou District are the surrounding urban area.

Figure 4 showed the geographical distribution of daily new COVID-19 deaths in Wuhan. The deaths were few in early January 2020, and gradually increased in late January. The epidemic situation in Wuhan was serious from the end of January to mid February, and then the number of daily deaths in each district gradually decreased in the late February.

Meanwhile, the geographical map showed that the COVID-19 epidemic situation in Wuhan had obvious regional differences. The epidemic situation in the central urban areas represented by Jianghan District were relatively serious, while the surrounding urban areas were relatively mild. As shown in Table 3, as of February 24, sort by residence, the top 3 regions in terms of death rate were $3.26 \%$ oo in Jianghan District, $2.65 \%$ o in Hannan District and 2.47\%oo in Jiang'an District. According to the medical facility where the death was, the top 3 regions ranked by death rate were $6.48 \%$ o in Hannan District, $4.26 \%$ oo in Dongxihu District and 2.46\%oo in Qingshan District.

As of February 24, the cumulative deaths in the central urban area accounted for $82.8 \%$ of the total deaths. The 
Table 1 The epidemiological characteristics of deceased patients of COVID-19 infection with different severities in Wuhan during the early stage

\begin{tabular}{|c|c|c|c|c|c|c|}
\hline \multirow[t]{2}{*}{ Baseline characteristics } & \multirow[t]{2}{*}{ Total } & \multicolumn{4}{|c|}{ Classification of severity $(\%)^{\mathbf{b}}$} & \multirow[b]{2}{*}{ Missing } \\
\hline & & Mild & Common & Severe & Critical & \\
\hline Total & 1833 & $682(37.2)$ & $101(5.5)$ & $551(30.1)$ & 249(13.6) & 250(13.6) \\
\hline \multicolumn{7}{|l|}{ Age } \\
\hline$M(I Q R)^{a}$ & $70.0(63.0-79.0)$ & $70.0(62.0-78.0)$ & $72.0(64.0-78.5)$ & $71.0(64.0-80.0)$ & $69.5(62.0-77.0)$ & $71.0(62.0-79.0)$ \\
\hline \multicolumn{7}{|l|}{ Sex } \\
\hline Male & $1211(66.1)$ & $438(64.2)$ & $71(70.3)$ & $371(67.3)$ & $155(62.2)$ & 176(70.4) \\
\hline Female & 622(33.9) & 244(35.8) & $30(29.7)$ & 180(32.7) & $94(37.8)$ & $74(29.6)$ \\
\hline \multicolumn{7}{|l|}{ Occupation } \\
\hline Child and student & $2(0.1)$ & $1(0.2)$ & $0(0.0)$ & $1(0.2)$ & $0(0.0)$ & $0(0.0)$ \\
\hline Cadre & $35(1.9)$ & $14(2.1)$ & $1(1.0)$ & $15(2.7)$ & $4(1.6)$ & $1(0.4)$ \\
\hline Freelancer & $7(0.4)$ & $2(0.3)$ & $1(1.0)$ & $1(0.2)$ & $3(1.2)$ & $0(0.0)$ \\
\hline Physical labor & $23(1.3)$ & $15(2.2)$ & $1(1.0)$ & $4(0.7)$ & $3(1.2)$ & $0(0.0)$ \\
\hline Public service staff & $25(1.4)$ & $14(2.1)$ & $0(0.0)$ & $8(1.5)$ & $2(0.8)$ & $1(0.4)$ \\
\hline Housework & $324(17.7)$ & 138(20.2) & 23(22.8) & 105(19.1) & $51(20.5)$ & $7(2.8)$ \\
\hline Retirees & $854(46.7)$ & $343(50.3)$ & $56(55.5)$ & $296(53.7)$ & $129(51.8)$ & $30(12.0)$ \\
\hline Farmer or worker & $66(3.6)$ & $29(4.3)$ & $4(4.0)$ & $22(4.0)$ & $10(4.0)$ & $1(0.4)$ \\
\hline Health worker & $8(0.4)$ & $3(0.4)$ & $1(1.0)$ & $3(0.5)$ & $1(0.4)$ & $0(0.0)$ \\
\hline Missing & $489(26.7)$ & 123(18.0) & 14(13.9) & $96(17.4)$ & $46(18.5)$ & $210(84.0)$ \\
\hline \multicolumn{7}{|l|}{ Underlying diseases } \\
\hline Yes & $1204(65.7)$ & $430(63.1)$ & $59(58.4)$ & $367(66.6)$ & 172(69.1) & 176(70.4) \\
\hline No & $583(31.8)$ & 234(34.3) & 38(37.6) & 173(31.4) & $68(27.3)$ & $70(28.0)$ \\
\hline Missing & $46(2.5)$ & $18(2.6)$ & $4(4.0)$ & $11(2.0)$ & $9(3.6)$ & $4(1.6)$ \\
\hline \multicolumn{7}{|c|}{ Specific Underlying diseases } \\
\hline \multicolumn{7}{|l|}{ Hypertension } \\
\hline Yes & $742(40.5)$ & 264(38.7) & $37(36.6)$ & 231(41.9) & $112(45.0)$ & $98(39.2)$ \\
\hline No & 1045(57.0) & $400(58.7)$ & $60(59.4)$ & $309(56.1)$ & $128(51.4)$ & 148(59.2) \\
\hline \multicolumn{7}{|l|}{ Diabetes } \\
\hline Yes & $357(19.5)$ & 133(19.5) & 18(17.8) & $110(20.0)$ & $50(20.1)$ & $46(18.4)$ \\
\hline No & $1430(78.0)$ & $531(77.9)$ & $79(78.2)$ & $430(78.0)$ & 190(76.3) & $200(80.0)$ \\
\hline \multicolumn{7}{|l|}{ Cardiovascular disease } \\
\hline Yes & $329(17.9)$ & 119(17.4) & $16(15.8)$ & 109(19.8) & $36(14.5)$ & $50(20.0)$ \\
\hline No & $1458(79.5)$ & $545(79.9)$ & $81(80.2)$ & $431(78.2)$ & 204(81.9) & 196(78.4) \\
\hline \multicolumn{7}{|l|}{ Respiratory disease } \\
\hline Yes & $152(8.3)$ & $47(6.9)$ & $9(8.9)$ & $57(10.3)$ & $18(7.2)$ & $21(8.4)$ \\
\hline No & 1635(89.2) & $617(90.5)$ & $88(87.1)$ & $483(87.7)$ & $222(89.2)$ & $225(90.0)$ \\
\hline \multicolumn{7}{|l|}{ Cancer (any) } \\
\hline Yes & $82(4.5)$ & $29(4.3)$ & $5(5.0)$ & $29(5.3)$ & $9(3.6)$ & $10(4.0)$ \\
\hline No & 1705(93.0) & 635(93.1) & $92(91.1)$ & $511(92.7)$ & $231(92.8)$ & 236(94.4) \\
\hline \multicolumn{7}{|l|}{ Date of onset } \\
\hline 2019.12-2020.1.9 & $147(8.0)$ & $27(4.0)$ & $5(5.0)$ & $37(6.7)$ & $32(12.9)$ & $46(18.4)$ \\
\hline 2020.1.10-1.21 & $525(28.6)$ & 154(22.6) & $11(10.9)$ & $149(27.0)$ & 79(31.7) & $132(52.8)$ \\
\hline 2020.1.22-2.1 & $869(47.4)$ & $391(57.3)$ & $42(41.6)$ & $288(52.3)$ & 107(43.0) & $41(16.4)$ \\
\hline $2020.2 .2-2.24$ & $288(15.7)$ & $110(16.1)$ & $43(42.6)$ & $77(14.0)$ & $31(12.4)$ & $27(10.8)$ \\
\hline
\end{tabular}


Table 1 The epidemiological characteristics of deceased patients of COVID-19 infection with different severities in Wuhan during the early stage (Continued)

\begin{tabular}{|c|c|c|c|c|c|c|}
\hline \multirow[t]{2}{*}{ Baseline characteristics } & \multirow[t]{2}{*}{ Total } & \multicolumn{4}{|c|}{ Classification of severity $(\%)^{\mathbf{b}}$} & \multirow[b]{2}{*}{ Missing } \\
\hline & & Mild & Common & Severe & Critical & \\
\hline Missing & $4(0.2)$ & $0(0.0)$ & $0(0.0)$ & $0(0.0)$ & $0(0.0)$ & $4(1.6)$ \\
\hline \multicolumn{7}{|l|}{ District of residence } \\
\hline Central urban area & 1384(75.5) & $574(84.2)$ & $87(86.1)$ & $428(77.7)$ & 199(79.9) & $96(38.4)$ \\
\hline Surrounding urban area & 286(15.6) & 102(15.0) & 13(12.9) & 108(19.6) & $41(16.5)$ & $22(8.8)$ \\
\hline Out of city & $28(1.5)$ & $6(0.9)$ & $1(1.0)$ & $12(2.2)$ & $5(2.0)$ & $4(1.6)$ \\
\hline Missing & 135(7.4) & $0(0.0)$ & $0(0.0)$ & $3(0.5)$ & $4(1.6)$ & $128(51.2)$ \\
\hline Days from onset to death, $M$ (IQR) & $17.0(12.0-22.0)$ & $17.0(12.0-22.0)$ & $16.0(10.0-22.0)$ & 17.0(13.0-23.0) & $17.0(12.0-23.0)$ & $16.0(10.0-23.0)$ \\
\hline Days from onset to diagnosis, $M$ (IQR) & 10.0(6.0-14.0) & $10.0(6.0-14.0)$ & $9.0(4.0-15.0)$ & 11.0(7.0-15.0) & 11.0(7.0-15.0) & $10.0(5.0-14.0)$ \\
\hline Days from diagnosis to deaths, $M$ (IQR) & $6.0(2.0-11.0)$ & $6.0(3.0-10.0)$ & $5.0(2.0-10.0)$ & $6.0(3.0-10.0)$ & $6.0(2.0-10.0)$ & $5.0(2.0-12.0)$ \\
\hline
\end{tabular}

${ }^{\mathrm{a} M}$ Medians, IQR Interquartile ranges;

${ }^{b}$ The classification of severity were according to the diagnostic criteria of the new coronavirus infection pneumonia diagnosis and treatment plan (trial fifth version)

death rate of the central urban areas $(2.05 \%$ oo $)$ was heavier than that of the surrounding areas $(0.65 \%$ oo). Due to the small population in Hannan District, the death rate was relatively high.

\section{Discussion}

Wuhan is the capital of Hubei Province and a megacity in central China. After the COVID-19 epidemic occurred in December 2019, strong prevention and control measures were taken to prevent the epidemic from spreading. Based on the stochastic transmission model, Adam J Kucharski showed that the median daily reproduction number in Wuhan declined from 2.35 (95\%CI: 1.15-4.77) per week before travel restrictions were introduced on Jan 23, 2020, to 1.05 (95\%CI: 0.412.39) per week after [6]. Research by Wang Xuyan showed that the COVID-19 epidemic in Hubei Province has gradually eased from mid to late February, and the prevention and control measures were very effective [7]. As of February 24, 2020, the number of daily deaths in Wuhan has shown a clear downward trend.

In the composition of deaths, mild type accounted for the largest proportion, $37.2 \%$, followed by severe type deaths, accounting for $30.1 \%$, and the initial diagnosis of the dead with underlying diseases is mostly mild type, so we should be alert to the deterioration of mild type.

Judging from the age distribution of diagnosed cases across the country, people of all ages are not resistant to the COVID-19 [5]. The analysis of the expert group also supported this view [8]. Older people and those with underlying diseases such as asthma, diabetes and heart disease may be at increased risk of infection [9]. In our

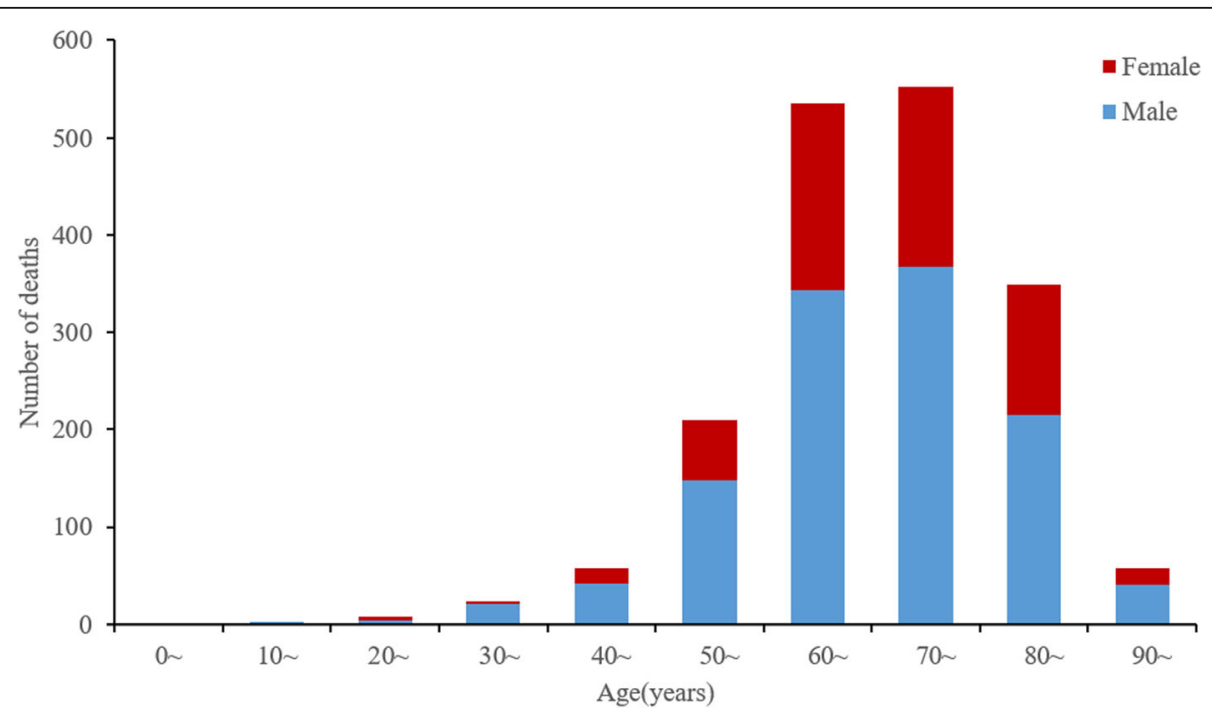

Fig. 1 The age distribution of deaths in Wuhan 


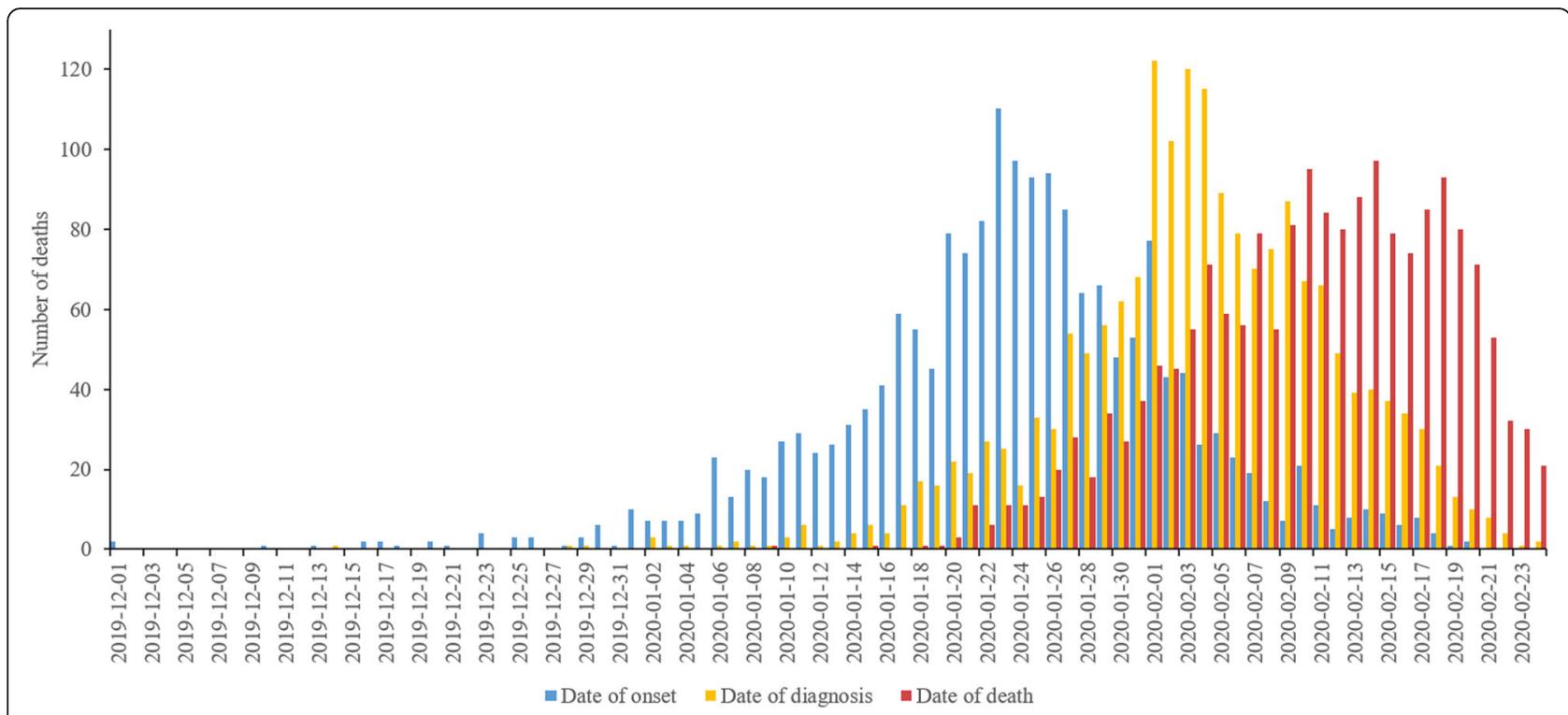

Fig. 2 The epidemiological curves by date of symptom onset, date of diagnosis and date of death in Wuhan

study, $65.7 \%$ of the deaths in Wuhan combined with underlying diseases, the main combined underlying diseases were hypertension, diabetes and cardiovascular diseases. Studies have shown that combination with underlying diseases such as hypertension, diabetes and cardiovascular disease may increase the mortality rate of COVID-19 patients [10-12]. It may be because the metabolic syndrome can downregulate the key mediator of the host's innate immune response to pathogenesis, affecting the function of the innate and humoral immune systems [13]. In addition, the pathogen of COVID-19, SARS-COV-2, is mainly bound to target cells by angiotensin-converting enzyme 2(ACE2) and ACE1 drugs are often used in cardiovascular disease patients, and long-term use of ACE1 can up-regulate the expression of ACE2 receptors in the body [14]. Thiazolidinedione in hypoglycemic drugs can also cause upregulation of ACE2 expression [15], which may aggravate the patient's symptoms.

The deaths in Wuhan were mainly middle-aged and elderly people, mainly concentrated in the age group of 50 89 years. It may be due to the weaker physical resistance of the middle-aged and elderly people and the higher probability of combining the underlying diseases. The minimum age of deaths is 14 years old, and no $0-9$ years old deaths occurred. SARS also has a low impact on children, considering the commonness of coronaviruses, children may be relatively unsusceptible to COVID-19 based on cellular structure or immunity [16]. There are no reports of COVID-19 causing maternal and infant deaths. In addition, the possibility of vertical transmission of coronavirus is very low. There are no recorded cases of vertical transmission of SARS or MERS $[17,18]$, and the COVID19 has not been confirmed vertical transmission [19-21].
The male to female ratio of confirmed cases issued by the China CDC was 0.99: 1 in Wuhan and 1.06: 1 in China overall [5], which indicated that men and women are equally susceptible to COVID-19. However, the fact that the sex ratio of deaths in Wuhan is 1.95: 1 showed male patients have a higher risk of death. As coronaviruses, SARS-CoV and COVID-19 have similar sex differences, probably because the $\mathrm{X}$ chromosome and estrogen can protect women from fatal infections [22, 23]. Our findings content with many reports that indicated being male is highly associated with death due to COVID-19. Men were at a higher risk of death due to COVID19 in India [24], the USA [25] and Brazil [26]. But in Nepal, female had a higher risk of death, this may because women in Nepal have higher smoking prevalence and higher risk of suffering from non-communicable diseases [27].

Among all occupational categories, the number of retirees' deaths was the largest, accounting for $46.7 \%$. And health workers often have close contact with patients during treatment, nursing, accompanying and visiting patients, the risk of nosocomial infection is high. Among the deaths, 8 health workers died with COVID-19, accounting for $0.4 \%$ of the total deaths. Children and students accounted for the least percentage of deaths, at $0.1 \%$. Studies have shown that the SARS-CoV-2 can use multiple homologous genes of angiotensin converting enzyme II (ACE2) to effectively replicate in human respiratory tract cells [28]. The relatively low incidence of child deaths may be due to the relatively weak function of ACE2 receptors in children, or low expression, which limits the path of viral invasion and avoids large-scale outbreaks in children [16]. 

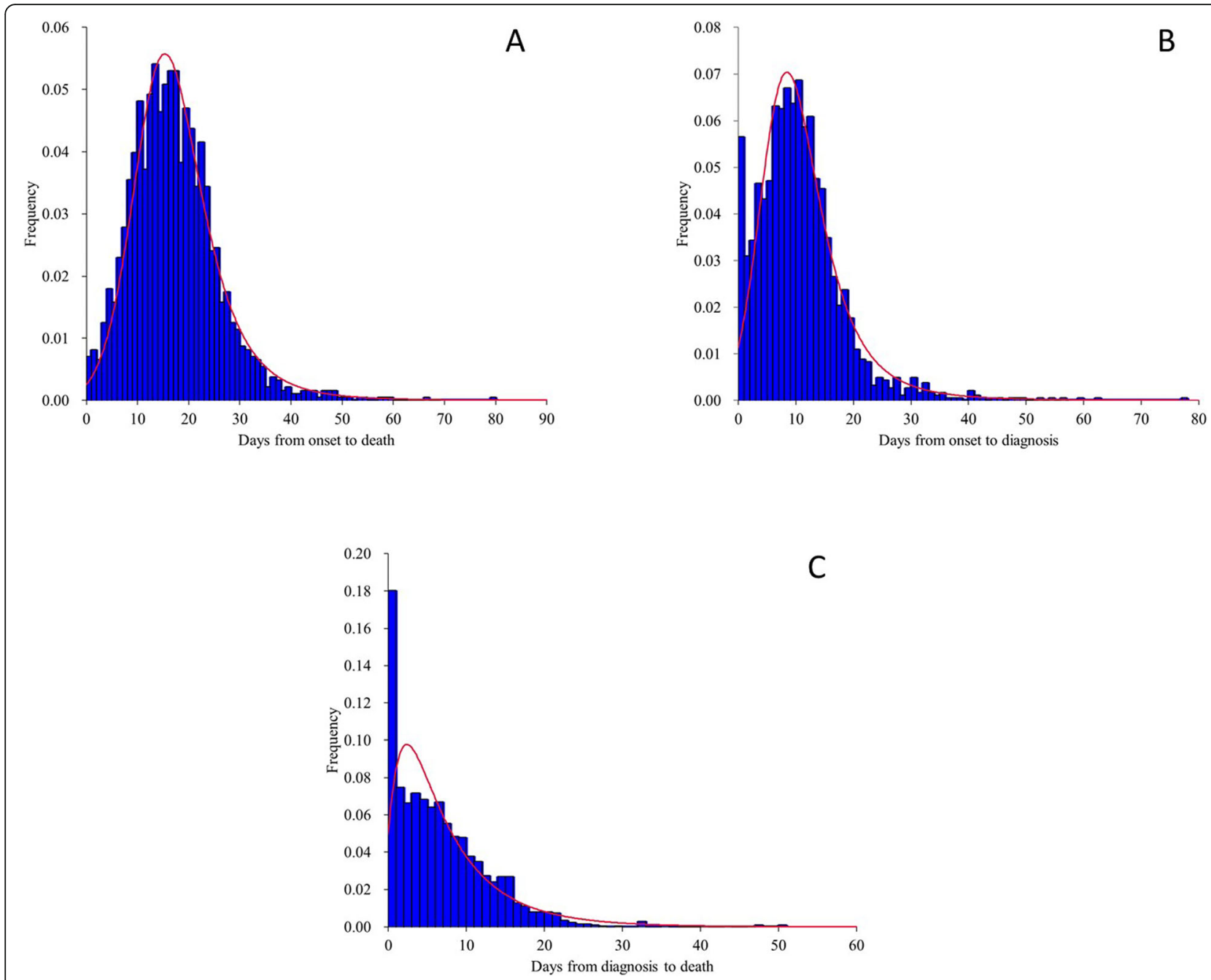

Fig. 3 Time distribution of interval from onset to death (a), interval from onset to diagnosis (b) and interval from diagnosis to death (c)

Analysis of 1833 deaths in Wuhan found that the mean interval from onset to diagnosis was 11.2 days; the median time was 10.0 days. Moreover, the interval from onset to diagnosis gradually shortened. For deaths with onset before January 15, between January 15-31 and after January 31, the median interval from onset to diagnosis is 15.0 days, 11.0 days and 5.0 days, respectively, indicating that the ability to discover and diagnose COVID-19 cases has gradually improved. Since January 23, Wuhan has adopted many epidemic prevention and control measures. After January 23, the median of interval from onset to diagnosis were reduced from 13.0 days to 8.0 days, which was significantly shorter than that before January 23 . This indicates that the early identification, isolation and confirmation of cases with COVID-19 have been accelerated in Wuhan. Shortening the duration of onset to diagnosis facilitates quarantine and reduces the risk of transmission, and the effective communicable period.

In addition, according to reports from India and Nepal, 1042 fatal cases (18.2\% of 5733 observed) were identified $\leq 24 \mathrm{~h}$ before death or posthumously in Tamil

Table 2 Distributional fits to key COVID-19 distributions

\begin{tabular}{|c|c|c|c|c|c|c|c|}
\hline Variable & Distribution & Parameter1 & Parameter2 & Parameter3 & Median & $25 \%$ & $75 \%$ \\
\hline Age & Weibull & 8.2152 & 89.42 & -14.41 & 71.1 & 62.4 & 78.6 \\
\hline Days from onset to death & Log Logistic & -14.513 & 31.184 & 6.8020 & 16.7 & 12.0 & 22.1 \\
\hline Days from onset to diagnosis & Log Logistic & -7.7179 & 17.669 & 4.7575 & 10.0 & 6.3 & 14.5 \\
\hline Days from diagnosis to deaths & InvGauss & 9.8986 & 19.1904 & -2.4969 & 5.4 & 2.6 & 10.0 \\
\hline
\end{tabular}


(a)
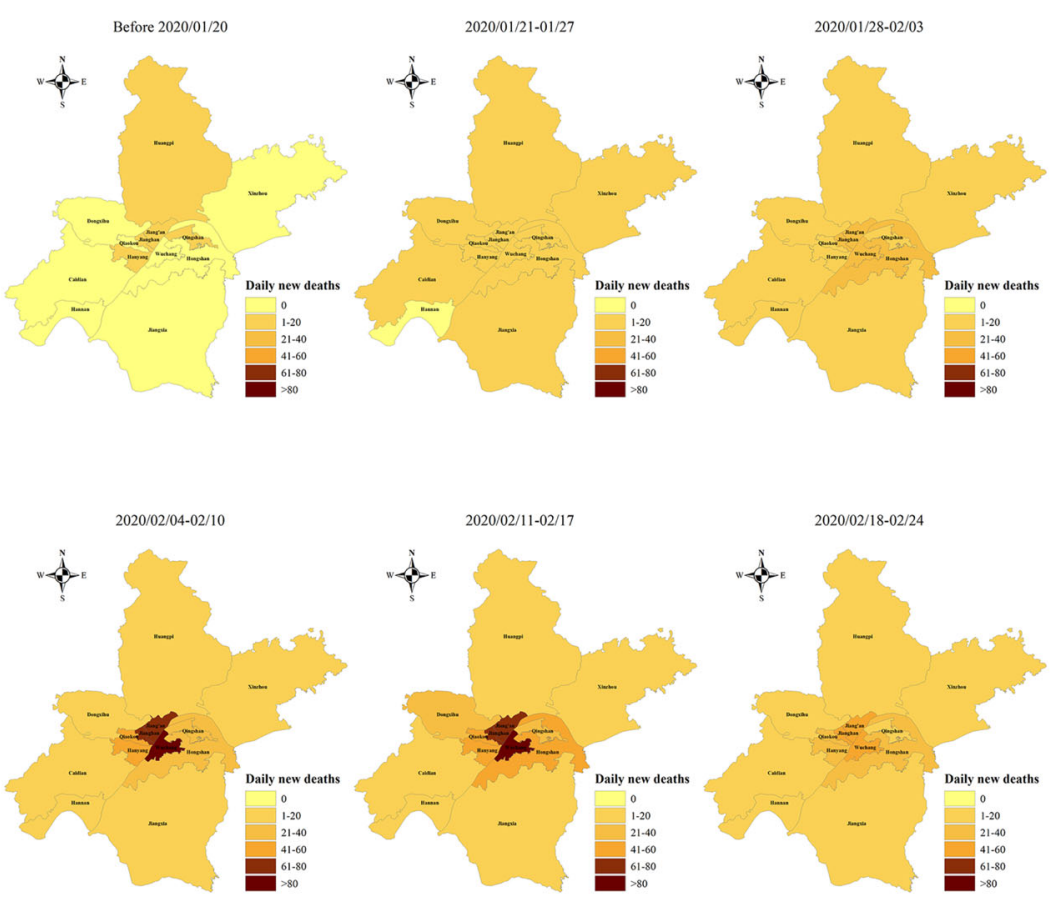

(b)

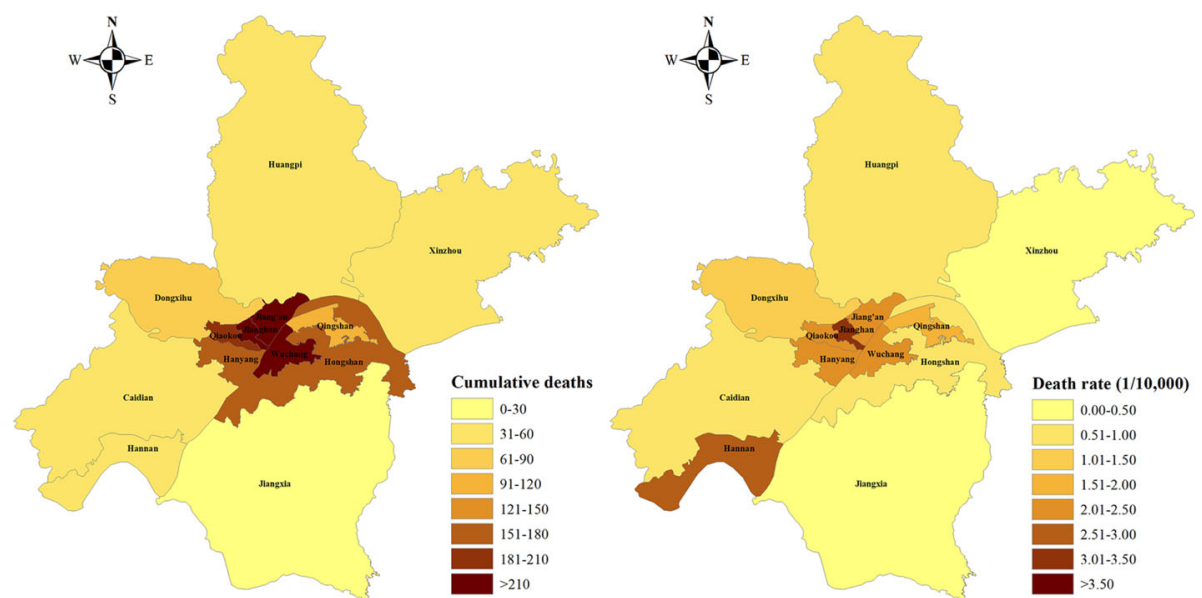

Fig. 4 a The geographic distribution of daily new COVID-19 death in administrative districts of Wuhan (2020/01 / 09-2020 / 02/24). b The geographic distribution of cumulative deaths and death rate in Wuhan

Nadu and Andhra Pradesh [24] and more than half of the individuals who died were diagnosed as SARS-CoV2-positive after death in Nepal [27]. Our database didn't support this analysis. However, according to the revised fifth version of the guideline over the diagnosis and treatment of COVID-19 [29], Clinical diagnosis was being used in Hubei Province only (China) form February 8 to February 19. Clinically diagnosed cases were diagnosed by symptoms, exposures and CT scan only.
Clinical diagnosis was effective, which is helpful to quarantine or treat infected cases as soon as possible, and prevent the epidemic from worsening.

According to the death data as of February 24, the first case of COVID-19 death in Wuhan was located in Huangpi District. The geographical map showed the distribution of COVID-19 epidemic in Wuhan had obvious regional differences. The central urban area was more serious than the surrounding urban areas. The 
Table 3 Death rate of COVID-19 cases in administrative districts of Wuhan

\begin{tabular}{|c|c|c|c|c|c|}
\hline \multirow[t]{2}{*}{ District } & \multirow{2}{*}{$\begin{array}{l}\text { Permanent } \\
\text { population } \\
(10,000)\end{array}$} & \multicolumn{2}{|l|}{ Residence } & \multicolumn{2}{|c|}{ Reporting Unit area } \\
\hline & & Deaths, N & Death rate per 10,000 residents & Deaths, N & Death rate per 10,000 residents \\
\hline Caidian & 76.16 & 43 & 0.56 & 153 & 2.01 \\
\hline Dongxihu & 58.48 & 79 & 1.35 & 249 & 4.26 \\
\hline Hannan & 13.58 & 36 & 2.65 & 88 & 6.48 \\
\hline Hanyang & 66.42 & 161 & 2.42 & 112 & 1.69 \\
\hline Hongshan & 167.73 & 159 & 0.95 & 164 & 0.98 \\
\hline Huangpi & 101.19 & 58 & 0.57 & 54 & 0.53 \\
\hline Jiang'an & 96.27 & 238 & 2.47 & 186 & 1.93 \\
\hline Jianghan & 72.97 & 238 & 3.26 & 170 & 2.33 \\
\hline Jiangxia & 96.20 & 29 & 0.30 & 32 & 0.33 \\
\hline Qiaokou & 86.87 & 181 & 2.08 & 167 & 1.92 \\
\hline Qingshan & 52.89 & 103 & 1.95 & 130 & 2.46 \\
\hline Wuchang & 128.28 & 299 & 2.33 & 303 & 2.36 \\
\hline Xinzhou & 91.06 & 41 & 0.45 & 25 & 0.27 \\
\hline
\end{tabular}

cumulative deaths reported in the central urban area accounted for $82.8 \%$. The death rate of COVID-19 in Wuhan was also the highest in the central urban area. This regional difference may be due to the fact that the Huanan Seafood Wholesale Market, the outbreak point, was located in Jianghan District, and the traffic in the central urban area was convenient, and the designated COVID-19 hospitals in the early stage of the epidemic were also located in the central urban area.

This study also has some limitations. First, some variables in this study have missing records, which may slightly affect the results. Second, the data on preexisting underlying diseases were based on self-report and we could not verify their validity. Third, the onset date of this study was obtained from the patient's selfreport, and there may be a recall bias.

In summary, the COVID-19 posed a great threat to the elderly, especially elderly men with underlying diseases living in non-central areas. The geographical distribution showed that the epidemic in the central area of Wuhan was more serious than that in the surrounding areas. The reduction in the interval from onset to diagnosis indicated a gradual improvement of the detection and diagnosis ability. The number of daily deaths in $\mathrm{Wu}$ han had continued to decline after February 14, indicating that the COVID-19 epidemic in Wuhan had achieved a tremendous improvement, and the strong epidemic control measures taken by Wuhan Government were very effective. Based on the above discussion, to further control the epidemic, it is necessary to carry out key monitoring, prevention and control of the elderly men, and strengthen early warning and intervention of severe and critical cases. Provide assistance to areas where health resources were relatively or limited.
Prevent hospital and health workers infections along with proper disposal of hospital wastes. Improving the detection and treatment capacity of hospitals and isolating the source of infection in time would be better options to control the disease spread.

\section{Supplementary Information}

The online version contains supplementary material available at https://doi. org/10.1186/s41256-020-00183-y.

Additional file 1: Table S1. The classification criteria of severity of COVID-19.

\section{Acknowledgements}

Not applicable.

Authors' contributions

CY supervised the study. CY, CJ, JB and FS designed the study. CY, JB, FS and HW collected and organized the data. JB and FS analyzed the data. JB, FS, $F W, S M, X L, Y U$ and JD interpreted the results. JB wrote the first draft. All authors read and approved the final manuscript

\section{Funding}

This project was supported by the National Key Research and Development Program of China (Grant No. 2017YFC1200502, 2018YFC1315302), the National Natural Science Foundation of China (Grant No. 81773552), Special Foundation for Basic Scientific Research of Central Universities (Grant No. 2020YJ066).

\section{Availability of data and materials}

The data that support the findings of this study are available from China CDC but restrictions apply to the availability of these data, which were used under license for the current study, and so are not publicly available. Data are however available from the authors upon reasonable request and with permission of China CDC. Medical Ethical Committees of Wuhan University (WHU2020-2020YF0031). 


\section{Consent for publication}

Not applicable.

\section{Competing interests}

The authors declare that they have no competing interests.

\section{Author details}

'Department of Epidemiology and Biostatistics, School of Health Sciences, Wuhan University, 115\#Donghu Road, Wuhan 430071, China. ${ }^{2}$ School of Public Health and Management, Hubei University of Medicine, 30\# South Renmin Road, Shiyan 442000, China. ${ }^{3}$ YEBIO Bioengineering Co., Ltd. of Qingdao, 21\# Aodongnan Road, Qingdao 266114, China. ${ }^{4}$ Global Health Institute, Wuhan University, 185\# Donghu Road, Wuhan 430072, China.

Received: 16 October 2020 Accepted: 7 December 2020

Published online: 21 December 2020

\section{References}

1. Al-Osail AM, Al-Wazzah MJ. The history and epidemiology of Middle East respiratory syndrome corona virus. Multidiscip Respir Med. 2017;12:20.

2. Chen $X$, Chughtai AA, Maclntyre CR. Application of a risk analysis tool to Middle East Respiratory Syndrome Coronavirus (MERS-CoV) outbreak in Saudi Arabia. Risk Anal. 2020;40(5):915-25.

3. Yang Y, Peng F, Wang R, et al. The deadly coronaviruses: the 2003 SARS pandemic and the 2020 novel coronavirus epidemic in China. J Autoimmun. 2020:109:102434.

4. WHO. Naming the coronavirus disease (COVID-19) and the virus that causes it. https://www.who.int/emergencies/diseases/novel-coronavirus-2019/ technical-guidance/naming-the-coronavirus-disease-(covid-2019)-and-thevirus-that-causes-it. Accessed 18 Mar 2020

5. The Novel Coronavirus Pneumonia Emergency Response Epidemiology Team. The epidemiological characteristics of an outbreak of 2019 novel coronavirus diseases (COVID-19) — China. Chin J Epidemiol. 2020;41(2):14551.

6. Kucharski AJ, Russell TW, Diamond C, et al. Early dynamics of transmission and control of COVID-19: a mathematical modelling study. Lancet Infect Dis. 2020:20(5):553-8.

7. Wang X, Yu Y, Hu Y, Yu C. COVID-19 analysis and forecast based on exponential smoothing model in Hubei Province. J Public Health Prev Med. 2020;31(1):1-4. (in Chinese).

8. YangY, Lu Q, et al. Epidemiological and clinical features of the 2019 novel coronavirus outbreak in China. medRxiv. 2020. https://doi.org/10.1101/2020. 02.10.20021675.

9. World Health Organization. Novel Coronavirus (2019-nCoV) advice for the public: Myth busters. https://www.who.int/emergencies/diseases/novelcoronavirus-2019/advice-for-public/myth-busters. Accessed 18 Mar 2020

10. Onder G, Rezza G, Brusaferro S. Case-Fatality Rate and Characteristics of Patients Dying in Relation to COVID-19 in Italy. JAMA. 2020;323(18):1775-6.

11. Yang $X, Y u Y, X u$ J, et al. Clinical course and outcomes of critically ill patients with SARS-CoV-2 pneumonia in Wuhan, China: a single-centered, retrospective, observational study. Lancet Respir Med. 2020;8(5):475-81.

12. Zhou F, Yu T, Du R, et al. Clinical course and risk factors for mortality of adult inpatients with COVID-19 in Wuhan, China: a retrospective cohort study. Lancet. 2020;395(10229):1054-62.

13. Justin I, Odegaard AC. Connecting type 1 and type 2 diabetes through innate immunity. Cold Spring Harb Perspect Med. 2012;2(3):a007724.

14. Li XC, Zhang J, Zhuo JL. The vasoprotective axes of the renin-angiotensin system: Physiological relevance and therapeutic implications in cardiovascular, hypertensive and kidney diseases. Pharmacol Res. 2017; 125(Pt A):21-38

15. Dariya B, Nagaraju GP. Understanding novel COVID-19: its impact on organ failure and risk assessment for diabetic and cancer patients. Cytokine Growth Factor Rev. 2020;53:43-52.

16. Fang F, Luo XP. Facing the major epidemic of new coronavirus infection in 2019: Thinking of pediatricians. Chin J Pediatr. 2020;58(2):81-5.

17. Alserehi H, Wali G, Alshukairi A, Alraddadi B. Impact of Middle East Respiratory Syndrome Coronavirus (MERS-CoV) on pregnancy and perinatal outcome. BMC Infect Dis. 2016:16(3):105.

18. Wong SF, Chow KM, Leung TN, et al. Pregnancy and perinatal outcomeof women with severe acute respiratory syndrome. Am J Obstet Gynecol. 2004;191(1):292-7.
19. Schwartz DA, Graham AL. Potential maternal and infant outcomes from (Wuhan) coronavirus 2019-nCoV infecting pregnant women: lessons from SARS, MERS, and other human coronavirus infections. Viruses. 2020;12(2): 194.

20. Zhu H, Wang L, Fang C, et al. Clinical analysis of 10 neonates born to mothers with 2019-nCoV pneumonia. Transl Pediatr. 2020;9(1):51-60.

21. Chen H, Guo J, Wang C, et al. Clinical characteristics and intrauterine vertical transmission potential of COVID-19 infection in nine pregnant women: a retrospective review of medical records. Lancet. 2020;395(10226):809-15.

22. Channappanavar R, Fett C, Mack M, Ten Eyck PP, Meyerholz DK, Perlman S. Sex-based differences in susceptibility to severe acute respiratory syndrome coronavirus infection. J Immunol. 2017;198(10):4046-53.

23. Chen N, Zhou M, Dong X, et al. Epidemiological and clinical characteristics of 99 cases of 2019 novel coronavirus pneumonia in Wuhan, China: a descriptive study. Lancet. 2020:395(10223):507-13.

24. Laxminarayan $R$, Wahl B, Dudala SR, et al. Epidemiology and transmission dynamics of COVID-19 in two Indian states. Science. 2020;370(6517):691-7.

25. Lewnard JA, Liu VX, Jackson ML, et al. Incidence, clinical outcomes, and transmission dynamics of severe coronavirus disease 2019 in California and Washington: prospective cohort study. BMJ. 2020;369:m1923.

26. de Souza WM, Buss LF, Candido DDS, et al. Epidemiological and clinical characteristics of the COVID-19 epidemic in Brazil. Nat Hum Behav. 2020; 4(8):856-65

27. Panthee B, Dhungana S, Panthee N, Gyawali S, Paudel A, Panthee S. Clinical and epidemiological features of COVID-19 deaths in Nepal. New Microbes New Infect. 2020;38:100797.

28. Heurich A, Hofmann-Winkler H, Gierer S, Liepold T, Jahn O, Pohlmann S. TMPRSS2 and ADAM17 cleave ACE2 differentially and only proteolysis by TMPRSS2 augments entry driven by the severe acute respiratory syndrome coronavirus spike protein. J Virol. 2014;88(2):1293-307.

29. Chinese Centers for Disease Control and Prevention. Notice on guideline over the diagnosis and treatment of COVID-19 (Revision version fifth). http://www.nhc.gov.cn/yzygj/s7653p/202002/d4b895337e19445f8d728fcaf1 e3e13a.shtml. Accessed 18 Mar 2020.

Ready to submit your research? Choose BMC and benefit from:

- fast, convenient online submission

- thorough peer review by experienced researchers in your field

- rapid publication on acceptance

- support for research data, including large and complex data types

- gold Open Access which fosters wider collaboration and increased citations

- maximum visibility for your research: over $100 \mathrm{M}$ website views per year

At $\mathrm{BMC}$, research is always in progress.

Learn more biomedcentral.com/submission 